\title{
Implementation of Customized Variable Insurance Management System Using Data Crawling and Fund Management Algorithm
}

\author{
Sung-hyun Nam ${ }^{1}$, Soon-kak Kwon ${ }^{2 *}$
}

\begin{abstract}
This paper accumulates the product structure data such as bond obligation ratio and investment ratio for variable insurance using crawling from the insurance company's API, also accumulates variable insurance income and project expenses for variable insurance using crawling from the API of life insurance association. From these accumulated data, the correlation coefficient between fund product and customer preference is calculated with an investment algorithm, and variable insurance funds by customer investment preference and product structure are recommended according to market conditions. From the simulation results, it is shown that the proposed variable insurance management system properly recommends and manages variable insurance according to customer preferences.
\end{abstract}

Key Words: Fund Management, Data Crawling, Variable Insurance Management.

\section{INTRODUCTION}

There are approximately 3,700 variable insurance products sold in Korea, and the structure is different for each variable insurance product. Since variable insurance has a different product structure, investment strategies must be managed differently for each product. Therefore, when investing in variable insurance, it is necessary to analyze variable insurance products, and then to consider a bottom-up investment method according to market conditions. In addition, yield management must be managed differently from stock-type funds.

As a system for managing variable insurance in Korea, a variable insurance fund management technology using a moving average line and a variable insurance fund recommendation technology based on market analysis data have been presented. The fund management technology in variable insurance using a moving average line determines the ratio between a stock-type fund and a bond-type fund according to a predetermined algorithm based on a 20-day moving average line and a 30 -week average purchase price. The variable insurance fund recommendation technology quantifies financial data that can affect the fund product and recommends a fund that fits the market situation. B.J. Lim [1] proposes a fund management method that dynamically changes the investment ratio of risky and safe assets according to the movement of the stock market. H.J. Lee [2] argued that the portfolio BSI significantly explains the portfolio return in high volatility stock portfolios with a high proportion of individual investors. Recently, fund investment systems through machine learning are studied. K.B. Nam [3] proposed a stock investment system through SVM (support vector machine) and kNN (k-nearest neighbor) algorithms. R. Akita [4] proposes the method of predicting stock prices by building LSTM model which is a neural network structure for handling time series data. X. Ding [5] proposes a neural network which combines the influence of long-term events and short-term events to predict stock prices. D.M. Nelson [6] predicts stock price movement using LSTM through five historic price measures and various technical indicators. L. C. Cheng [7] applies an attention mechanism [8] to a neural network for predict stock prices.

The existing variable insurance management systems technologies focus on stock management rather than variable insurance analysis. Stock funds and variable insurance are similar that they are investment products, but

\footnotetext{
Manuscript received December 27, 2020; Revised February 22, 2021; Accepted March 02, 2021. (ID No. JMIS-20M-12-049)

Corresponding Author (*): Soon-kak Kwon, Eomgang-ro 176, Busanjin-gu, Busan, Republic of Korea, 47340, +82-51-890-1727, skkwon@deu.ac.kr.

${ }^{1}$ Dept. of Artificial Intelligence, Dong-eui University, hkwmnsh@gmail.com

${ }^{2}$ Dept. of Computer Software Engineering, Dong-eui University, skkwon@deu.ac.kr
} 
there are many differences in their management methods and product structure. In variable insurance funds, various indicators related to stocks influence the rate of return. In the variable insurance funds, it is important to understand the stock market as part of the insurance premium is invested in stocks and bonds [9]. However, the product structure also should be considered for analyzing the variable insurance funds [10]. Insurers with variable insurance want to invest according to their investment preferences. Therefore, variable insurance fund management should be managed according to the customer preferences [11].

Existing variable insurance management systems may have a daily fund change period depending on market conditions. The fund change signal structures for the existing systems can have good results in terms of profitability, but can have very dangerous consequences in terms of stability. However, the target rate of return for variable insurance is much lower than that of general stock funds. Therefore, profitability should be considered, but long-term stability should be considered. Variable insurance requires a system that avoids frequent trading and pursues a target rate of return as a fund management method only for variable insurance. This paper proposes a stable variable insurance management system.

\section{DESIGN OF CUSTOMIZED VARIABLE INSURANCE MANAGEMENT SYSTEM USING DATA CRAWLING AND FUND MANAGEMENT ALGORITHM}

The system proposed in this paper is designed using web crawling technology and fund management algorithm. First, it is necessary to design a variable insurance system through web crawling technology. Web crawler is a program that navigates the world wide web in a systematic and automated way of www (world wide web). Crawling data through the web is called a web crawler, and it is called web crawling or spidering [12-13]. Web crawling is primarily used to make copies of every page on web site, and search engines index pages created through web crawling for quicker searches. Web crawling is a form of software agent and is usually provided by a list of URLs called seeds. Web crawling recognizes all hyperlinks on the page and extracts and updates a list of URLs.

The proposed method analyzes products by variable insurance within the product by accessing the variable insurance DB of each insurance company. The variable insurance DB provided by the insurance association. The proposed method crawls the financial data integration API of insurance association and insurance company and identifies project costs, fund management, guarantee options, additional payments, coverage, and product types.
Then the proposed method determines the characteristics of about 3700 variable insurance products. It allows consumers to identify variable insurance products by easily analyzing pension and insurance payments and fund management performance. Each insurance company data is stored in its own DB and applied to the variable insurance fund management system.

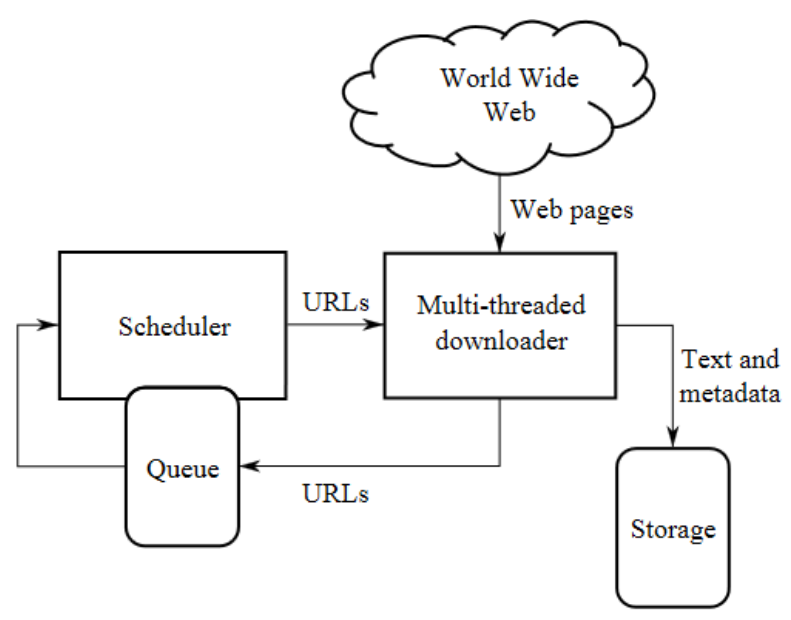

Fig. 1. Data crawler structure.

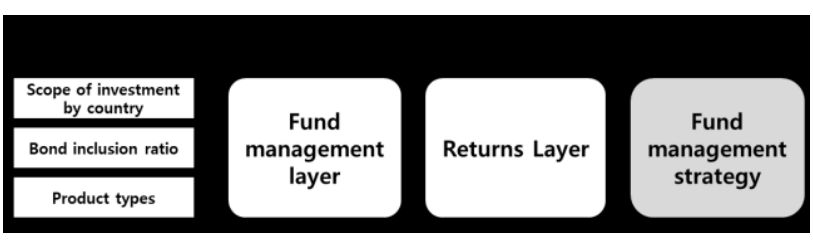

Fig. 2. Design of reclassification of variable insurance products through crawling data.

Next, the filtered variable insurance products are classified into new product types, the target rate of return is determined according to the classified products, and a fund management algorithm system for variable insurance for each product is designed.

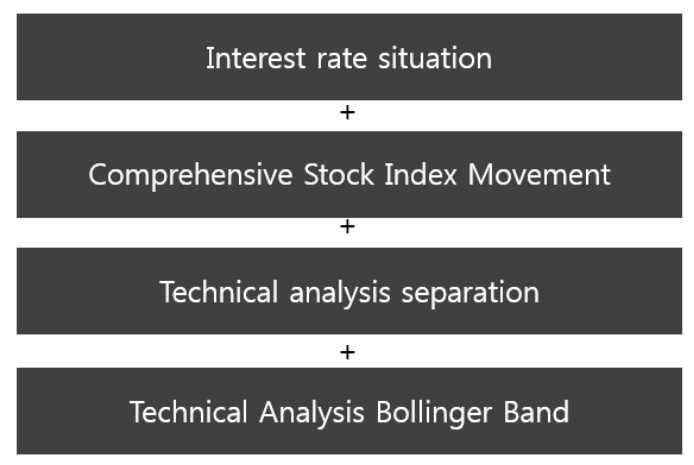

Fig. 3. Value of variable insurance system.

Finally, the fund management algorithm introduces four investment theories. This system is designed to generate a 
fund change signal when a certain score is reached to prevent frequent fund change signals. In the case of general stock-type fund products, frequent fund change signals are generated, but as transactions become more frequent, there is a trap of probability that causes loss, so when a certain value is reached, a fund change signal is generated to prevent frequent trading.

\section{IMPLEMENTATION OF CUSTOMIZED VARIABLE INSURANCE MANAGEMENT SYSTEM}

We implement the management system of customized variable insurance management system. The flow of implemented system is shown in Fig. 4.

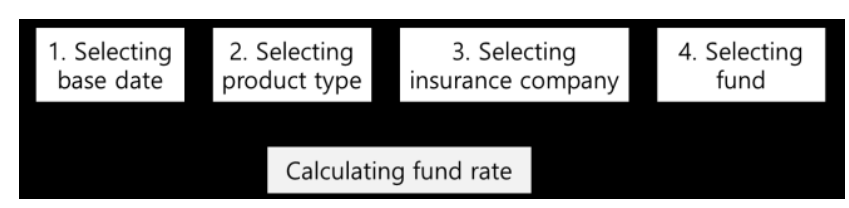

Fig. 4. Flow of customized variable insurance management system.

First, variable insurance data is collected by crawling data which is provided from the life insurance association and each insurance company. Afterwards, the variable insurance information such as based data, product type, insurance company are transmitted. The example code for information transmission is as follows:

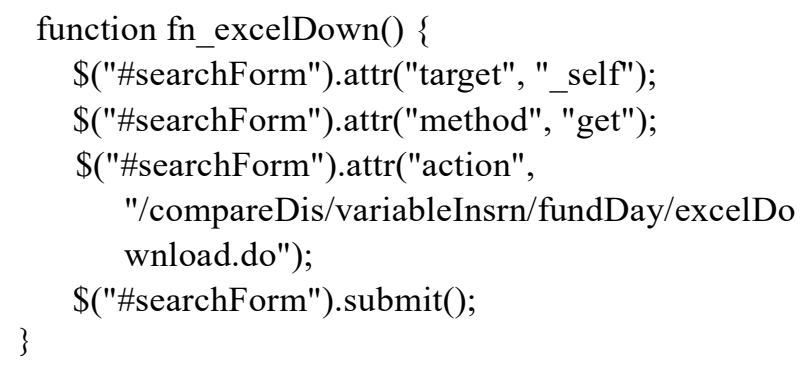

After receiving the file of the insurance information data corresponding to the entered information, values of each field in the file is obtained by parsing. This process is repeated at a specific period in the server through scheduling.

We design filtering to classify variable insurance products into new fund types by applying the variables shown in Fig. 5 from the crawled data. It implements a customized fund recommendation system through a fund management algorithm for filtered product data. The fund algorithm is classified according to the stock investment rate of variable insurance products.

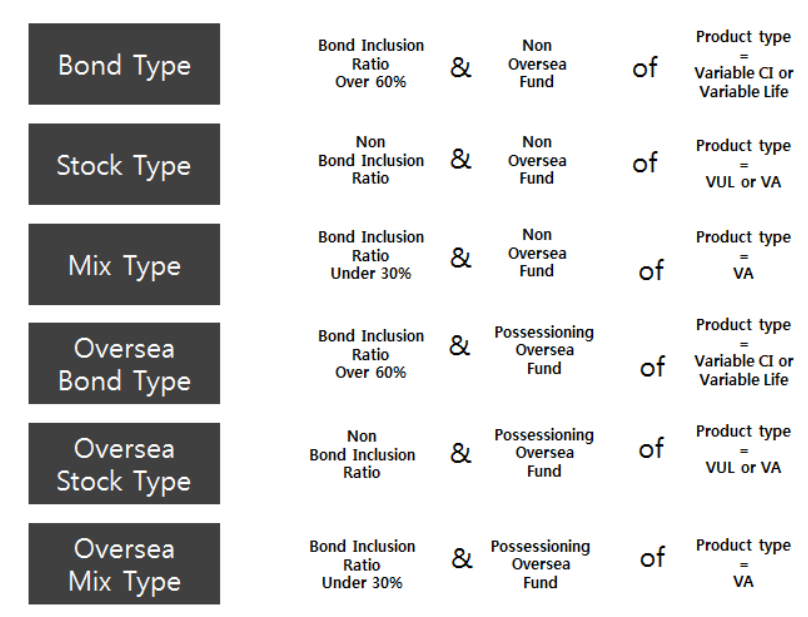

Fig. 5. Reclassification calculation method of variable insurance product.

Fund based on stock investment ratio is classified such as stock type of stock investment ratio exceeding 70\%, stock mixed type of stock investment ratio 60 69\%, mixed type of stock investment ratio 40 59\%, bond mixed type of stock investment ratio 30 39\%, bond type of stock investment ratio $0 \sim 29 \%$, and points are given according to rise and fall of interest rate. When the interest rate rises, +1 and +2 points are added for the stock mixed type and the stock type, respectively, and when the interest rate falls, +1 and +2 points for the bond mixed type and the bond type as additional points. Then, the separation of the current composite stock price index is calculated by taking into the account of the 20th day line. For 80 to 89 points, the stock type is added as +2 points, 90 to 99 points, the stock type and the stock mixed type are added as +1 point. For 101 points to 110 points, the bond mixed type and the bond type are added as +1 point, and for 111 to 120 points, the bond type are added as +2 points. Finally, the Bollinger band score is calculated, and the variable insurance fund with the highest score is recommended.

Selling and buying signals are generated by applying the Bollinger Band, a technique that identifies mid- to longterm trends and analyzes the stock price by forming an upper limit, a lower limit, and a center line based on 200 days. A strong buy signal is generated when the representative listing index for each country approaches within the $1 \%$ error range of the lower limit of the Bollinger Band. A strong sell signal and a sell signal are generated when the index approaches within the $1 \%$ error range of the upper limit and within the $1 \%$ error range of the center line, respectively. Expected return is calculated by the interval difference between the upper, center and lower limits of the Bollinger band. 
Implementation of Customized Variable Insurance Management System Using Data Crawling and Fund Management Algorithm

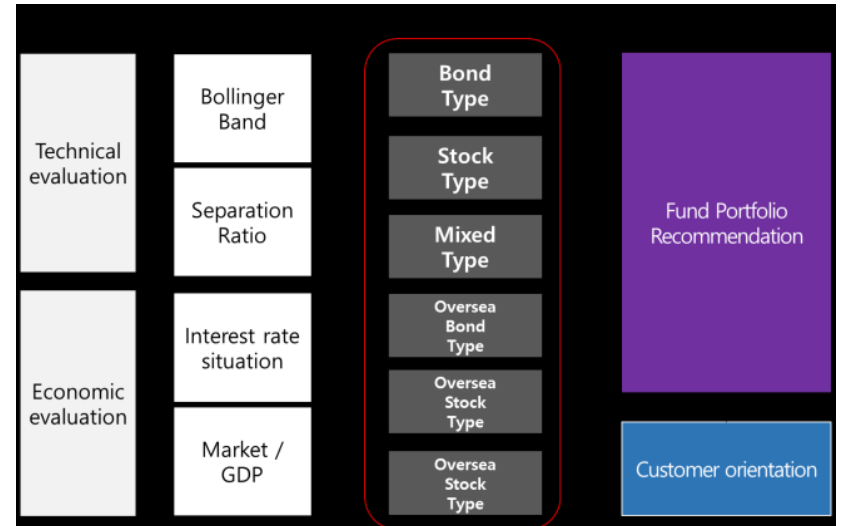

Fig. 6. The proposed fund management system structure.

\section{SIMULATION RESULTS}

When the stock market rises, the fund management of the variable insurance management system, which is relatively conservatively operated, has a lower return than that of general stock-type funds, but when the stock market declines, the fund management of the variable insurance system has higher returns than the stock-type fund. Due to the characteristics of variable insurance products, it is more advantageous to operate the variable insurance management system in a structure that is more stable than a high rate of return and does not cause any losses in operating the product over the long term. The Korean stock market (KOSPI) can be roughly divided into a rising period, a falling period, and a sideways view, and the following is a comparative analysis of the returns on fund management through a general stock fund and a variable insurance system. For comparative analysis, the growth stock type of MetLife life insurance was selected as a comparative sample. The reason for choosing the fund is that the beta coefficient is the closest to that of domestic stocks, so it was possible to reach a relatively accurate figure according to the stock market fluctuations. The stock market was on a downtrend from January 28, 2020 to March 20, 2020, and the fund management return was $-32.76 \%$.

During this period, there was one fund change signal through the variable insurance system, and the operating return for that period was $1.25 \%$. The stock market was in a sideways phase from February 13, 2019 to December 31, 2019 , with a fund management return of $6.67 \%$. During this period, there was one fund change signal through the variable insurance system, and the return of fund management for that period was $10.12 \%$.

The stock market was on an uptrend from April 14, 2020 to December 8, 2020, the fund management yield was $53.44 \%$, the fund change signal through the variable insurance system occurred twice, and the operating yield was $39.52 \%$.
Table 1. Periodic return of growth stock type.

\begin{tabular}{|c|c|c|}
\hline \multirow{2}{*}{ Decline Period } & Period & Fund period return \\
\cline { 2 - 3 } & $2020.01 .28 . \sim 03.20$. & -32.76 \\
\hline Sideways Period & $2019.02 .13 . \sim 12.31$. & $6.67 \%$ \\
\hline Growth Period & $2020.04 .14 . \sim 12.08$. & $53.44 \%$ \\
\hline
\end{tabular}

Table 2. Fund management return status through variable insurance system.

\begin{tabular}{|c|c|c|}
\hline & $\begin{array}{c}\text { Variable insurance } \\
\text { fund trading signal }\end{array}$ & $\begin{array}{c}\text { Variable insurance } \\
\text { management system } \\
\text { periodic rate of return }\end{array}$ \\
\hline Decline Period & Once & $1.25 \%$ \\
\hline Sideways Period & Once & $10.12 \%$ \\
\cline { 2 - 3 } Growth Period & Twice & $39.52 \%$ \\
\hline
\end{tabular}

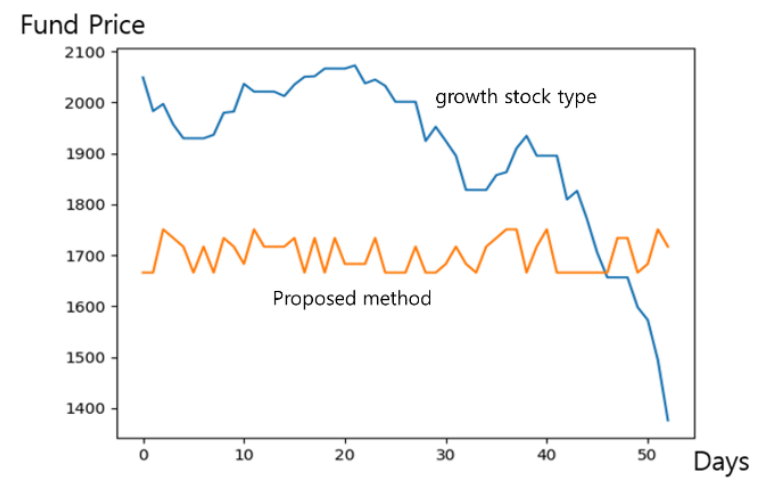

Fig. 7. Comparison of operating return rate for decline period.

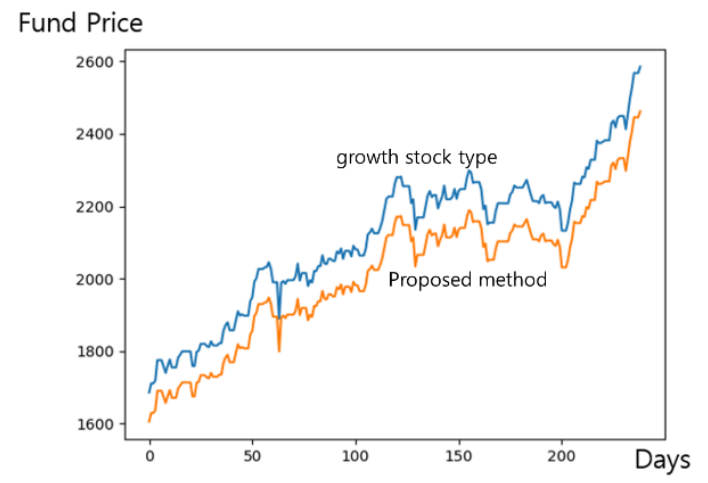

Fig. 8. Comparison of operating return rate for growth period.

Fig. 9 shows the return on fund management during the sideways period, and shows that fund management through the variable insurance system during the period has higher returns than that of general stock funds management. Fig. 7 shows higher performance than general stock fund management through variable insurance fund management when stock prices fall. Fig. 8 shows that the fund price of a general stock type exceeds the rate of return of fund management through the variable insurance system between the stock market sideways. Variable insurance is a 
long-term financial product so that must have a stable return in the long term. In the period of stock growth, the rate of return is slightly lower than that of general stock fund management.

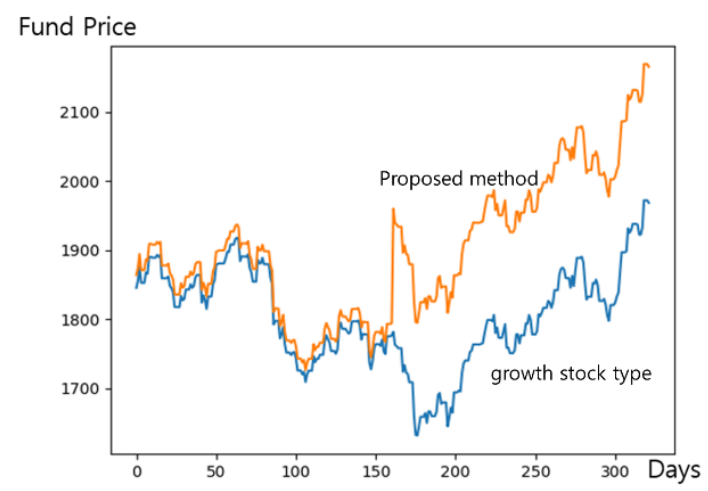

Fig. 9. Comparison of operating return rate for sideways period

\section{CONCLUSION}

When variable insurance is managed through the stock product management algorithm, the timing of fund change occurs every day, but the variable insurance management system refrains from frequent fund change in consideration of market conditions. When a strong buy signal occurs, the fund change signal is generated to increase profitability. An algorithm that simultaneously pursues stability was substituted. Since the fund portfolio and product type of about 3700 variable products are different, it is a variable insurance fund management system through product analysis. An investment model was created according to the customer orientation model. By simulating the return on investment for each customer disposition, a fund recommendation model tailored to the customer disposition was created, and when the customer disposition and fund status were input, it was possible to recommend a fund appropriate to the customer disposition.

The proposed method uniformly evaluates the scores of economic situation and stock graph through the technical indicators. Therefore, a lot of historical data needs to be accumulated for accurate proposal of a fund portfolio. In addition, it may need to adjust the weight for each fund after data accumulation. The variable insurance funds have a structure that proposes a fund folio according to the current market conditions. Therefore, the current contents must be supplemented if a new investment type fund type is appeared.

\section{Acknowledgement}

This research was supported by the BB21+ Project in 2020 and the MSIT (Ministry of Science and ICT), Korea, under the Grand Information Technology Research Center support program (IITP-2021-0-01791) supervised by the IITP (Institute for Information \& communications Technology Planning \& Evaluation).

\section{REFERENCES}

[1] B. J. Lim, "A Study on Risk Management of Variable Insurance GMXB Using Portfolio Insurance Strategy," The Journal of Actuarial Science, vol. 7, no. 2, pp. 55$81,2015$.

[2] H. J. Lee, "A Cross-sectional Analysis on the Impact of Individual's Sentiment on Return Comovement," Journal of Finance \& Knowledge Studies, vol. 12, no. 1, pp. 177-204, 2014.

[3] K. B. Nam, J. S. Jang, H. Oh, and T. H. Kim, "Development of Stock Investment System Using Machine Learning," Proceeding of KIPS Fall Conference 2017, pp. 810-812, 2017.

[4] R. Akita, A. Yoshihara, T. Matsubara, and K. Uehara, "Deep Learning for Stock Prediction Using Numerical and Textual Information," Proceeding of IEEE/ACIS International Conference on Computer and Information Science, pp. 1-6, 2016.

[5] X. Ding, Y. Zhang, T. Liu, and J. Duan, “Deep Learning for Event-driven Stock Prediction," Proceeding of the International Joint Conference on Artificial Intelligence, pp. 2327-2333, 2015.

[6] D. M. Nelson, A. C. Pereira, and R. A. Oliveira, "Stock Market's Price Movement Prediction with LSTM Neural Networks," Proceeding of the International Joint Conference on Neural Networks, pp. 1419-1426, 2017.

[7] L. Cheng, Y. Huang, and M. Wu, "Applied Attentionbased LSTM Neural Networks in Stock Prediction," in Proceeding of the IEEE International Conference on Big Data, pp. 4716-4718, 2018.

[8] D. Bahdanau, K. Cho, and Y. Bengio, "Neural Machine Translation by Jointly Learning to Align and Translate,' arXiv preprint arXiv: 1409.0473, pp. 1-15, 2014.

[9] Y. M. Kim, "Examining the Determinants of Knowledge Sharing: Analysis of Insurance and Fund Flows with a Focus on Variable Insurance," Journal of Business Research, vol. 30, no. 2, pp. 31-50, 2015.

[10] Y. J. Kwon and S. Y. Kim, "Guaranteed Minimum Accumulated Benefit in Variable Annuities and Jump Risk," Journal of the Korea Contents Association, vol. 20, no. 11, pp. 281-291, 2020.

[11] S. Y. Yoo, "A Study on the Differential Application of 
Warranty Costs in Variable Life Insurance," Study of Actuarial Science, vol. 7, no. 1, pp. 39-72, 2015.

[12] L. Seung, S. J. Yun, and Y. W. Woo, "Crawling Methods for Web Data of Various Formats Using Python," in Proceeding of KIICE Fall Conference, pp. 343-346, 2019.

[13] C. W. Na and B. W. On, "A Proposal on A Proactive Crawling Approach with Analysis of State-of-the-art Web Crawling Algorithms," Journal of Internet Computing and Services, vol. 20, no. 3, pp. 43-59, 2019.

\section{Authors}

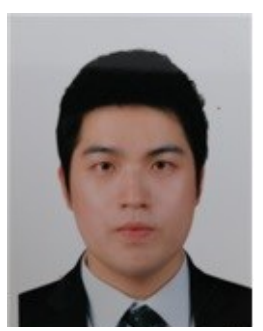

Sung-hyun Nam (hkwmnsh@gmail.com) received the B.S. degree in Economic and the M.S. degree in Computer Software Engineering from Dong-eui University in 2008 and in 2021, respectively, and is currently a Ph.D. course in the Department of Artificial Intelligence at Dong-eui University. His research interest is in the areas of big data algorithm.

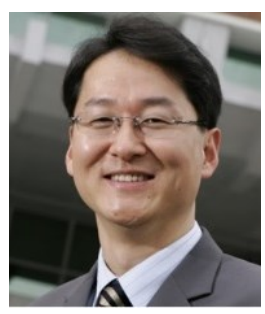

Soon-kak Kwon (skkwon@deu.ac.kr) received the B.S. degree in Electronic Engineering from Kyungpook National University, in 1990, the M.S. and Ph.D. degrees in Electrical Engineering from Korea Advanced Institute of Science and Technology (KAIST), in 1992 and 1998, respectively. From 1998 to 2000, he was a team manager at Technology Appraisal Center of Korea Technology Guarantee Fund. Since 2001, he has been a faculty member of Dong-eui University, where he is now a professor in the Department of Computer Software Engineering. From 2003 to 2004, he was a visiting professor of the Department of Electrical Engineering in the University of Texas at Arlington. From 2010 to 2011, he was an international visiting research associate in the School of Engineering and Advanced Technology in Massey University. Prof. Kwon received the awards, Leading Engineers of the World 2008 and Foremost Engineers of the World 2008, from IBC, and best papers from Korea Multimedia Society, respectively. His biographical profile has been included in the 2008 2014, 2017 2019 Editions of Marquis Who's Who in the World and the 2009/2010 Edition of IBC Outstanding 2000 Intellectuals of the 21 st Century. $\mathrm{He}$ is an associate editor for IEICE Nolta journal, a topic editor for MDPI Electronics journal, and a reviewer board member for MDPI Signals journal. Also he is working as a reviewer for several journals such as Sensors, Applied Sciences, Information, Symmetry, Entropy, IEEE TCSVT, and IEEE Access. His research interests are in the areas of image processing, video processing, video transmission, depth data processing, and $\mathrm{AI}$ object recognition. 